Biocontrol Science, 2017, Vol. 22, No. 1, 55-59

Note

\title{
Occurrence of Cronobacter spp. in Dried Foods, Fresh Vegetables and Soil
}

\begin{abstract}
SHIGEKO UEDA*
Laboratory of Hygiene, Kagawa Nutrition University, 3-9-1 Chiyoda, Sakado-shi, Saitama 350-0214, Japan

Received 29 July, 2016/Accepted 26 September, 2016

The present study surveyed the occurrence of Cronobacter spp. in dried foods including milk powder, spices and herbs and others, and fresh vegetables commercially available in markets, and ground soil materials for the agriculture. Cronobacter spp. were isolated from $15 \%$ of 33 spice and herb samples and $3 \%$ of 36 taste foods, and these were $C$. turicensis, $C$. malonaticus, $C$. sakazakii and C. dubliensis. Cronobacter spp. from fresh vegetables were detected in $12 \%$ of field vegetables and $13 \%$ of hydroponic vegetables. C. turicensis was prevalent in field vegetables, and C. malonaticus was in hydroponic ones. And, Cronobacter spp. in shredded vegetables were detected from $44 \%$ of 9 samples, and these were C. dubliensis, C. turicensis and C. sakazakii. Also, Cronobacter spp. in soil from rice field, vegetable field and sandpits were predominantly $C$. sakazakii and C. malonaticus.
\end{abstract}

Key words : Cronobacter spp. / Dried food / Fresh vegetables / Soil.

Cronobacter spp. are recognized as opportunistic pathogens causing rarely life-threating infections such as meningitis, necrotizing enterocolitis and bacteremia in premature, low-birth and immunocompromised infants (FAOMHO, 2008). Particularly, it should be paid attention that infants given contaminated milk formula suffered from meningitis, enteritis and sepsis (Simmons et al., 1989; Van Acker et al., 2001). Therefore, the bacteria should be considered as one of agents of foodborne illnesses.

Cronobacter spp. are gram-negative, facultative anaerobic, nonspore-forming, motile bacteria belonging to the family Enterobacteriaceae. Iversen et al., (2008) described that the species consisted of $S$. sakazakii, $C$. dublinensis, C. dublinensis subsp. dublinensis, C. dublinensis subsp. lactaridi, C. dublinensis subsp. lausannensis, C. malonaticus, C. muytjensii, C. turicensis and the unnamed genotype species I. Thereafter, C. condimenti and C. univeralis were added in 2012 (Joseph et al., 2012), and C. helventicus, C. pulveris and C. zurichensis were added in 2013 (Brady el al., 2013). The natural habitat of these bacteria is unknown, but the various growth properties suggests that Cronobacter spp. are associated with plants (Schmid et al., 2009).

*Corresponding author. Tel: +81-49-282-7343, Fax: +81-49282-3717, E-mail : ueda(a)eiyo.ac.jp
Cronobacter spp. have been isolated in various environmental materials such as soil, water, dust from household and milk powder factories, and utensils used to mix infant formula (Neelam et al., 1987; Friedemann, 2007, Kndhai et al., 2004; Muytjens et al., 1983). Moreover, Cronobacter spp. have been isolated from a wide spectrum of foods and food ingredients (Friedmann, 2007). The present survey aimed to investigate the occurrence of Cronobacter spp. in dried foods including milk powder, spices and herbs and others, and fresh vegetables commercially available in markets, and ground soil materials for the agriculture, and the bacterial isolates were identified by means of standard biochemical tests.

A total of 228 samples of dried foods were purchased from retailers in Kantoh area. Their survey was examined on 33 kinds of dried spices and herbs, 64 of powdered milk products, 11 of dried fruits, 7 of sea food products, 36 of dried taste foods, 49 of convenience foods and 28 of other dried type-foods. Also, a total of 123 samples of fresh vegetables obtained from retailers in Saitama prefecture. The fresh vegetables were 60 samples harvested from outdoor fields, 54 samples cultured hydroponically and 9 samples of shredded vegetable. In addition, soil samples were collected from 25 of rice fields, 26 of vegetable fields, 24 of flower beds and 25 of park sandpits in Saitama 
prefecture.

The detection and isolation of Cronobacter spp. were performed according to the procedure described in the directive CSN P ISO/TS 22964 (2006) Milk and milk products - Detection of Enterobacter sakazakii. Briefly, aliquots ( $5 \mathrm{~g}$ or $10 \mathrm{~g}$ ) of each of tested samples were weighed separately and aseptically into sterile stomacher bags, diluted with 45 or $90 \mathrm{ml}$ of buffered peptone water (Oxoid, UK), and homogenized in a stomacher for $2 \mathrm{~min}$. The homogenate was incubated at $37^{\circ} \mathrm{C}$ for $18 \mathrm{~h}$. Then, $0.1 \mathrm{ml}$ of the pre-enriched sample was transferred into $10 \mathrm{ml}$ of Lauryl Sulfate Broth (Oxoid, UK) supplemented with $\mathrm{NaCl}$ to a final concentration of 34 $\mathrm{mg} / \mathrm{ml}$ and vancomycin to a final concentration of 0.01 $\mathrm{mg} / \mathrm{ml}$. The sample was incubated at $44^{\circ} \mathrm{C}$ for $24 \mathrm{~h}$. One loop of the selectively enriched culture was streaked onto the surface of Chromocult Enterobacter Sakazakii Agar (ESA; Merck, Germany) and incubated at $44^{\circ} \mathrm{C}$ for 24 h. Green or blue-green colonies which were termed presumptive Cronobacter spp. were streaked onto Trypticase Soy Agar (Difco, USA) to make a pure culture. After incubation at $25^{\circ} \mathrm{C}$ for $48 \mathrm{~h}$, the purity of the culture could be checked by confirming that all colonies were yellow. Their identification was by means of biochemical tests. In addition to Gram staining and phenotype characterization derived from commercial API ID 32 E (bioMeriux CZ, Czech Republic) devices according to procedure's instructions, the following tests were performed using conventional manual methods: motility test, methyl red test, reduction of nitrate, gas formation from D-glucose, production of catalase, cytochrome oxidase test, indole production, utilization of malonate, and acid production from dulcitol.

The standard plate counts and the qualitative detection results of coliform bacteria and Cronobacters spp. from dried foods, fresh vegetables and soil samples were shown in Table 1. The average plate counts in dried foods were $2.1 \pm 1.2 \mathrm{Log} \mathrm{CFU} / \mathrm{g}$, and the counts were higher in spices and herbs, and sea foods than other dried food. Coliforms were detected only in 1 (14\%) sample among seafood samples. Cronobacter spp. were detected from 5 (15\%) of 33 kinds of spices and herbs and 1 (3\%) of 36 taste foods. The detection frequency of Cronobacter spp. was especially high in herbs and

TABLE 1. Incidences of standard plate counts, coliform bacteria, Cronobacter spp. in dried foods, fresh vegetables and soil samples.

\begin{tabular}{|c|c|c|c|c|}
\hline & \multirow{2}{*}{$\begin{array}{l}\text { No. of } \\
\text { samples }\end{array}$} & \multirow{2}{*}{$\begin{array}{c}\mathrm{SPC}^{1)} \\
\log \text { CFU/g }\end{array}$} & \multicolumn{2}{|c|}{ No. (\%) of positive samples: } \\
\hline & & & Coliforms $^{2)}$ & Cronobacter spp. ${ }^{3)}$ \\
\hline \multicolumn{5}{|l|}{ Dried foods } \\
\hline Spices and Herbs & 33 & $3.0 \pm 1.4$ & & $5(15 \%)$ \\
\hline Powdered milk & 64 & $1.2 \pm 0.4$ & & \\
\hline Dried fruits & 11 & $1.5 \pm 0.7$ & & \\
\hline Sea foods & 7 & $3.8 \pm 1.1$ & $1(14 \%)$ & \\
\hline Dried taste foods & 36 & $1.5 \pm 0.5$ & & $1(3 \%)$ \\
\hline Convenience foods & 49 & $2.0 \pm 0.8$ & & \\
\hline Other & 28 & $2.0 \pm 1.1$ & & \\
\hline Total & 228 & $2.1 \pm 1.2$ & $1(0.4 \%)$ & $6(2.6 \%)$ \\
\hline \multicolumn{5}{|l|}{ Fresh vegetables } \\
\hline from Fields & 60 & $3.6 \pm 0.9$ & $38(63 \%)$ & $7(12 \%)$ \\
\hline Hydroponic cutures & 54 & $4.7 \pm 0.4$ & $37(69 \%)$ & $7(13 \%)$ \\
\hline Shredded vegetables & 9 & $4.5 \pm 0.1$ & $8(89 \%)$ & $4(44 \%)$ \\
\hline \multicolumn{5}{|l|}{ Soil } \\
\hline Rice fields & 25 & $6.0 \pm 0.2$ & $5(20 \%)$ & $1(4 \%)$ \\
\hline Vegetable fields & 26 & $6,1 \pm 0.3$ & $4(15 \%)$ & $4(15 \%)$ \\
\hline Flower beds & 25 & $5.9 \pm 0.2$ & $10(40 \%)$ & \\
\hline Sandboxes & 24 & $5.0 \pm 0.7$ & $7(29 \%)$ & $8(33 \%)$ \\
\hline
\end{tabular}

1) SPC: Standard plate counts

2) Coliforms were estimated by conventional MPN assay with $5.55 \mathrm{~g}$ of samples.

3) Cronobacter spp. were detected after 5 or $10 \mathrm{~g}$ of samples were precultuered in buffered peptone water $37^{\circ} \mathrm{C}$ for $18 \mathrm{~h}$. 
TABLE 2. Occurrence of Cronobacter spp. in dried food, fresh vegetable and soil samples.

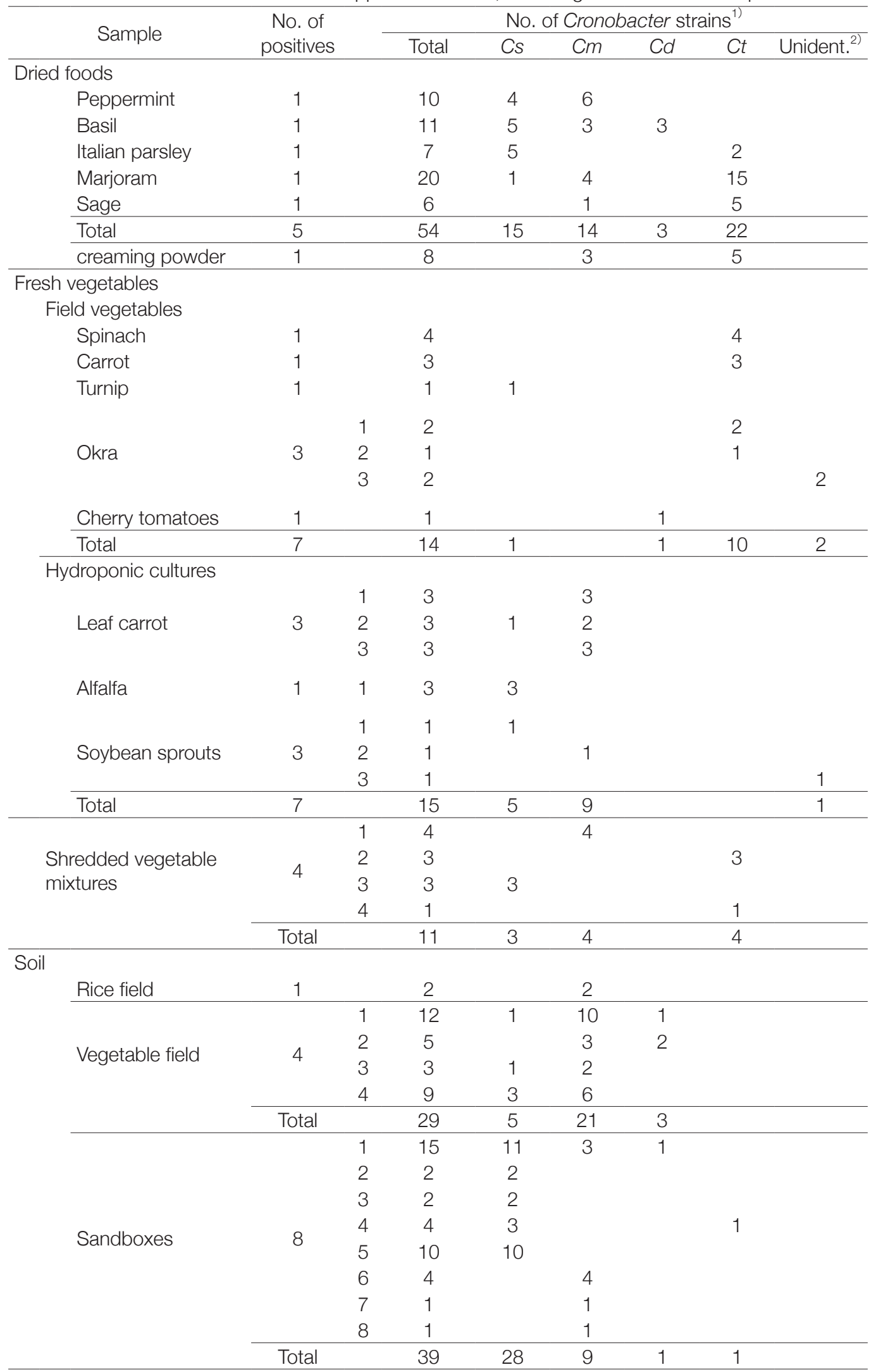

1) Cs: C. sakazakii; Cm: C. malonaticus; Cd: C. dublinensis; Ct: C. turicensis

2) Unident.: Unidentification 
spices, but other 222 dried food samples except 1 taste food (creaming powder) were not contaminated with Cronobacter spp. On fresh vegetables, the average standard plate counts were $3.6 \pm 0.9 \mathrm{Log} \mathrm{CFU} / \mathrm{g}$ in ones from fields, and $4.7 \pm 0.4 \mathrm{Log}$ CFU/g in hydroponic cultures, while coliforms were detected in $38(63 \%)$ among 60 of field vegetables, and in 37 of 54 (69\%) hydroponic vegetables. Also, Cronobacter spp. were detected in $7(12 \%)$ of field vegetables and 7 (13\%) of hydroponic vegetables. In commercial artificially shredded vegetables, the average plate counts were $4.5 \pm 0.1$ Log CFU/g, coliforms were detected in 8 of 9 (89\%) samples, and Cronobacter spp. were isolated from 4 of 9 (44\%) samples. On soil samples, the standard plate counts were $6 \mathrm{Log} \mathrm{CFU} / \mathrm{g}$ in rice fields, vegetable fields and flower beds, but $5 \mathrm{Log}$ CFU/g in the samples from sandboxes. Coliforms from soil samples were detected in 5 of $25(20 \%)$ rice field samples, $4(15 \%)$ of 26 vegetable field ones, 10 of 25 (40\%) flower bed ones, and 7 of 24 (29\%) sandbox ones. Also, Cronobacter spp. were isolated from 1 (4\%) of rice field samples, 4 (15\%) of vegetable field ones, and 8 (33\%) of sandbox ones, but they were not detected from all flower bed samples. Ogihara et al. (2014) suggested that there were positive correlations between the viable-coliforms counts and Cronobacter counts as reported by Jung and Park (2006). But, samples contaminated with Cronobacter were not necessarily contaminated with coliforms and high levels of the plate counts.

The species of Cronobacter spp. isolated from dried food, fresh vegetable and soil samples were shown in Table 2. Among dried foods, Cronobacter spp. were isolated from 5 kinds of spices and herbs containing peppermint, basil, Italian parsley, marjoram and sage, and creaming powder. The identified Cronobacter spp. were C. turicensis (44\%), C. malonaticus (27\%), C. sakazakii (24\%) and C. dubliensis (5\%). Five kinds of fresh vegetables (spinach, carrot, turnip, okra and cherry tomatoes) from fields were contaminated with $C$. turicensis (71\%), C. sakazakii (7\%) and C. dubliensis (7\%). Leaf carrot, alfalfa and soybean sprouts among vegetables cultured hydroponically were contaminated with C. malonaticus (60\%) and C. sakazakii (33\%). Also, C. dubliensis (36\%), C. turicensis (36\%) and C. sakazakii (27\%) were isolated from 4 commercially shredded vegetable samples. Although Hochel et al. (2012) and Ogihara et al. (2014) surveyed dried foods and food materials other than dried foods on incidences of Cronobacter spp., of which $C$. sakazakii was the most common contaminant, and some differences were recognized every food samples as for the distribution of Cronobacter species. On soil materials, Cronobacter spp. from 1 rice field was $C$. malonaticus only, whereas the common species from 4 vegetable fields were $C$. malonaticus (74\%) and C. sakazakii (17\%), and the common species from 8 sandboxes in parks were $C$. sakazakii (72\%) and C. malonaticus (23\%). In the present survey, the members of Cronobacter spp. were different among material types, and Cronobacter members were not necessarily found between dried foods, fresh vegetables and soil materials.

The members of Cronobacter spp. are ubiquitous bacteria that have been found in various foods particularly of plant origin and dried material. Some spice and herb materials and fresh vegetables tested in the present survey were contaminated with low level of Cronobacter spp. Although an impact of the consumption of contaminated foods on infants, elderly or immunocompromised individuals is not sufficient, addition of spices and herbs after cooking or handling of fresh vegetables should be noted in kitchen since Cronobacter spp. can multiply at room temperature, and conventional hygienic handling of foods would be required to control the viable bacterial counts, especially of Cronobacter spp.

\section{REFERENCES}

Brady, C., Cleenwerck, I., Venter, S., Coutiho, T., and De Vos, P. (2013) Taxonomic evaluation of the genus Enterobacter based on multilocus sequence analysis. Syst. Appl. Microbiol., 36, 309-319.

FAO/WHO (2008) Enterobacter sakazakii (Cronobacter spp.) in powdered follow-up formula. Microbiological Risk assessment Series No. 15, 90pp. Rome: FDAWHO.

Friedmann, M. (2007) Enterobacter sakazakii in foods beverages (other than infant formula and milk powder). Int. J. Food Microbiol., 116, 1-10.

Hochel, I., Ruzickova, H., Krasny, L., and Demnerova, K. (2012) Occurrence of Cronobacter spp. in retail foods. J. Appl. Microbiol., 112, 1257-1265

Iversen, C., Mullane, N., Cardell, B., Tall, B. D., LehnerA., Faning, S., Stephan, R., and Joosten, H (2008) Cronobacter gen. nov., a new genus to accommodate the biogroups of Enterobacter sakazakii, and proposal of Cronobacter sakazakii gen. nov., comb. nov., Int. J. Syst. Evol. Microbiol., 58, 1442-1447.

Joseph, S., Centikaya, E., Drahovska, H., Levican, A., Figueras, M. J., and Forsthe, S. J. (2012) Cronobacter condiment sp. nov., isolated from spiced meat, and Cronobacter universalis sp. nov., a species designation for Cronobacter sp. genospecies 1, recovered from a leg infection, water and food ingredients. Int. J. Syst. Evol. Microbiol., 62, 1277-1283.

Jung, M-K., and Park, J-H. (2006) Prevalence and thermal stability of Enterobacter sakazakii from unprocessed readyto-eat agricultural products and powdered infant fomula. Food Sci. Biotechnol., 15, 152-157.

Kandhai, M. C., Reij, M. W., Gorris, L. G. M., GuillaumeGentil, O., and van Schothrorst, M. (2004) Occurrence of Enterobacter sakazakii in the food production environments and households. Lancet, $363:$ 39-40.

Muytjens, H. L., Zanen, H. C., Sondeerkamp, H. J., Kollee, L. A., Waschmuth, I. K., and Farmer, J. J. II (1983) Analysis 
of eight cases of neonatal meningitis and sepsis due to Enterobacter sakazakii. J. Clin. Microbiol., 18, 115-120.

Neelam, M., Nawaz, Z., and Riazuddin, S. (1987) Hydrocarbon biodegradation, biochemical characterization of bacteria isolated from local soil. Pak. J. Sci. Ind. Res., 30, 382-385.

Ogiwara, H., Kiribe, N., Fukuda, N., Furukawa, S., Morinaga, Y., and Igimi, S. (2014) Cronobacter spp. in commercially available dried food in Japan. Biocontrol Sci., 19, 209-213.

Schmid, M., Iversen, I., Gontia, I., Stephan, R., Hoffmann, A., Hartmann, A., Jha, B., and Riedel, K. (2009) Evidence for a plant-associated natural habitat for Cronobacter spp. Res. Microbiol., 160, 608-614.

Simmons, B. P., Gelfand, M. S., Haas, M., Metts, L., and Ferguson, J. (1989) Enterobacter sakazakii infections in neonates associated with intrinsic contamination of powdered infant formula. Infect. Control Hosp. Epidemiol., 10, 398-401.

Van Acker, J., De Smet, F., Muyldermans, G., Bougatef, A., Naessens, A., and Lauwers, S. (2001) Outbreak of necrotizing enterocolitis associated with Enterobacter sakazakii in powdered milk formula. J. Clin. Microbiol., 39, 293-297. 